\title{
RESEARCH ON THE MECHANICAL BEHAVIOR OF SOME ALUMINUM-BASED ALLOYS
}

\author{
Mirabela Georgiana MINCIUNĂ ${ }^{1,2}$, Petrică VIZUREANU1,2,* \\ 1"Gheorghe Asachi" Technical University of Iasi, Faculty of Materials Science and Engineering, \\ Blvd. Mangeron, No. 51, 700050, Iasi, Romania \\ ${ }^{2}$ Centre of Excellence Geopolymer and Green Technology (CEGeoGTech), \\ Universiti Malaysia Perlis (UniMAP), 01000 Perlis, Malaysia.
}

\begin{abstract}
The mechanical properties of Al-Si alloys have been investigated. Abrasion wear resistance is an important analysis being used in various applications so there are many laboratory testing methods to determine it. In this article, we've looked at one of the ways to determine wear resistance using a scratch tester as a relatively easy, efficient, and fast test method. Materials used in the tests were: Al-Si (Al 94.30; Si 2.24, Fe 0.84) alloy. The coefficient of friction and wear of the samples were determined both by the methods of testing the wear and by investigating them in correlation with their mechanical properties.
\end{abstract}

Keywords: Al-Si alloy, resistance, coefficient of friction, microstructure

\section{Introduction}

Deformable $\mathrm{Al}$ and $\mathrm{Si}$ alloys have about $1 \% \mathrm{Si}$ and additions of $\mathrm{Mg}, \mathrm{Mn}$, Ti to increase strength. They are hardy alloys by heat treatment of artificial hardening and ageing, due to the formation of the compound $\mathrm{Mg} 2 \mathrm{Si}$ with variable solubility. Foundry Al-Si alloys, known as silumines, have the best casting properties of $\mathrm{Al}$ alloys [1-5].

They are alloys with $4-18 \% \mathrm{Si}$, simple or complex alloys with $\mathrm{Cu}, \mathrm{Mg}, \mathrm{Fe}, \mathrm{Ni}, \mathrm{Mn}$. The most used are alloys with $11-14 \% \mathrm{Si}$. Upon slow cooling of the alloys by about $13 \% \mathrm{Si}$, primary crystals of $\mathrm{Si}$ appear in the structure, coarse eutectic of solid solution $\alpha$ of $\mathrm{Si}$ in $\mathrm{Al}$ and acicular crystals of Si. To finish the granulation, the alloys are poured into the shell (metal moulds), under pressure or modified [6-7]. Parts made of metallic materials (metals or alloys), used with the greatest weight in the construction of machinery and equipment, are subjected during use (operation) to the action of external mechanical loads (forces).

As a result of the action of external forces, in these parts, the so-called internal forces or efforts are created and the parts are deformed.

Abrasion wear is considered one of the most common types of wear, in most applications abrasion wear resistance is considered to be the most important.

Most wear defects (over 50\%) are due to abrasive wear. This situation has become a major problem in major industries. In the automotive industry, for example, it can be found in most parts such as cylinder, piston, segments, cylinder head, brakes, etc., as well as other types of machines operating in various contaminated environments, construction machinery, agricultural machinery, wind turbines [8-10]. 
A significant part of the company's costs is represented by the prices associated with the use of the machines. The wear and tear of equipment is a loss, both in terms of cost and performance.

The fight against wear and tear and the prolongation of the life of specialized equipment is an extremely urgent task.

Physical wear and tear can damage the equipment, increase the risk of damage and accidents, and significantly shorten the life of the parts. The occurrence of wear leads to a high increase in waste, risk of accidents, but also high production and maintenance costs.

Investigations of the surfaces of the Al-Si layers subjected to scratch tests are a very important parameter, in this situation the load acts between the material used and the tip of the indenter. The obtained results are presented after scratching material and show two ways of deforming the analysed sample: brittle and ductile [11-15].

Aluminium has attractive properties such as ease of manufacture, low density, good corrosion resistance, high weight-strength ratio and high breaking hardness. All these properties make aluminium one of the most economical materials, with low production costs, and structurally the most efficient material used for the construction of various automotive, military, technical and commercial equipment [16-20].

In this article, we looked at the coefficient of friction under dry conditions and the scratch test for an Al-Si-based alloy, which is known as a high wear-resistant alloy.

We analysed the coefficient of friction and wear of the aluminium-based alloy both with the help of abrasion resistance testing methods and in correlation with their mechanical properties.

\section{Materials and Methods}

The behaviour of a part to the mechanical stresses produced by external forces depends on certain properties specific to the metallic material from which the part is made, called mechanical properties. Usually, the mechanical properties of metallic material are determined by mechanical tests, consisting of the application of specimens in conditions suitable for highlighting the properties sought.

The part subjected to mechanical stress is a device for discharging water at high pressures (fig. 1), type TRAPI, which falls into the class of Al-Si alloys (Al 94.30, Si 2.24, Fe 0.84, Mn $0.60, \mathrm{Mg} \mathrm{0.50,} \mathrm{Ni} 0.24$ other items).

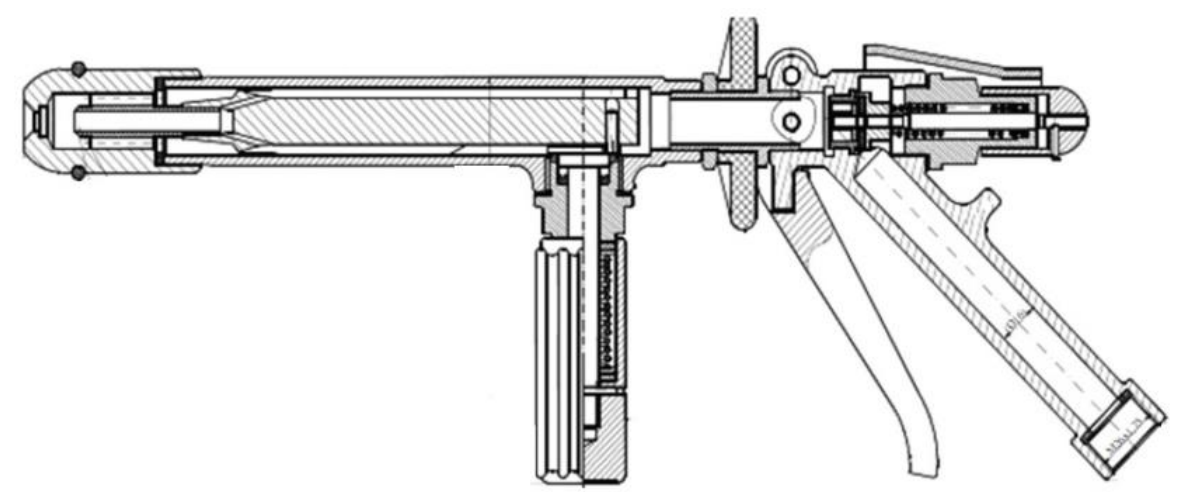

Fig. 1. Overall dimensions for pistol TRAPI [13]

With the help of mechanical tests, qualitative results are obtained regarding the behaviour of metallic materials under the conditions of demand in terms of these tests but also the values of conventional or physical quantities, called mechanical characteristics. 
The CETR UMT-2 tribometer can be used to analyse the following tribological processes:

- determination of static and dynamic micro and nanometric scale friction forces and coefficients of friction in rotating motion for various combinations of materials;

- study of stick-slip processes at the micro and nanometric scale;

- study of adhesion forces at the micro and nanometric scale;

- study of wear processes at micro and nanometric scale;

- study of resistance to micro and nano scratching of surface layers;

- determinations of hardness and modulus of elasticity by micro and nanoindentation.

The values for the measurable compressive and frictional forces are between $0.1 \mathrm{mN}$ and $20 \mathrm{~N}$, with a resolution between $1 \mu \mathrm{N}$ and $1 \mathrm{mN}$, depending on the measuring range of the force sensors. The tribometer covers the following force ranges: $0.1 \mathrm{mN} \div 10 \mathrm{mN}, 5 \mathrm{mN} \div 500 \mathrm{mN}$ and $0.2 \mathrm{~N} \div 20 \mathrm{~N}$.

For the study of the processes of wear, indentation and micro scratching (micro scratch) the device is equipped with:

- a pin and disc wear monitoring system, with an accuracy of 0.25 microns;

- an indenter with a diamond tip at $120^{\circ}$ and a tip radius of 200 microns;

- a system of linear horizontal displacement (Y direction) with the fixing mass of the sample for testing the resistance to micro scratching, with the displacement accuracy of up to 1 micron, having a stroke of at least $75 \mathrm{~mm}$, with variable speeds between $0.001 \mathrm{~mm} / \mathrm{s}$ up to 10 $\mathrm{mm} / \mathrm{s}$, with the possibility of developing a displacement force in the process of micro scratching up to $1000 \mathrm{~N}$.

To monitor the processes of friction and wear by acoustic emission (AE) the tribometer has:

- equipment for $\mathrm{AE}$ monitoring of the friction and wear processes from the pin / balldisc contacts, with the possibility of storing and analysing the signal in correlation with the friction and wear diagrams;

- sensor frequency range: $0.2 \mathrm{MHz} \div 5 \mathrm{MHz}$;

- the degree of amplification of the AE signal: maximum $60 \mathrm{~dB}$.

To monitor interruptions of film or deposited layers, the device has: disc;

- equipment for monitoring the electrical resistance of the contact between pin/ball and

- range of electrical resistances of the contacts: from $5 \mathrm{MOhm}$ to $1 \mathrm{MOhm}$.

The tribometer is equipped with sensors for normal force and friction force for the following working ranges: $0.1 \mathrm{mN} \div 10 \mathrm{mN}, 5 \mathrm{mN} \div 500 \mathrm{mN}$ and $0.2 \mathrm{~N} \div 20 \mathrm{~N}$ with the measurement accuracy of $1 \mu \mathrm{N}, 10 \mu \mathrm{N}$ and $1 \mathrm{mN}$.

The indentation test consists of two main steps: an initial preload step with a force of up to $10 \%$ of the maximum test force and a loading step with a force of up to $450 \mathrm{~N}$, depending on the force range of the force sensor. on which the indentation test is performed.

\section{Results and Discussion}

\section{Determination of coefficient of friction in dry conditions}

The microtribometer was used directly to measure the friction force. The friction force $F_{f}$ acts on the elastic blade of the sensor and the acquisition of data from the force sensor is done with a Vishay P3 voltage indicator and the recording is done on the computer, using appropriate software. The measuring system was calibrated using loads ranging from 0.5 grams to 5 grams $(5 \mathrm{mN}$ to $50 \mathrm{mN})$. During the experiment, the friction force $\mathrm{Ff}$ is determined directly, and the coefficient of friction is determined as the ratio between Ff and the normal load G. 


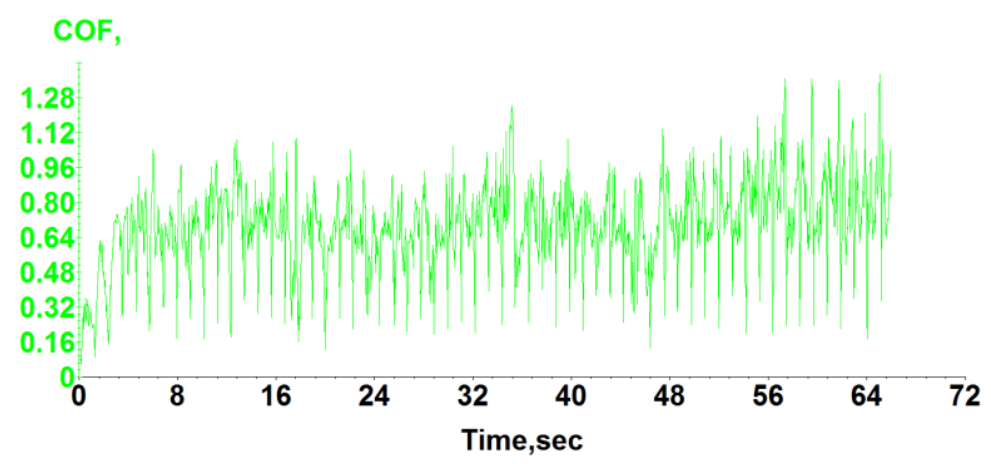

Fig. 2. Variation of the coefficient of friction in relation to time

Figure 2 shows the variation of the coefficient of friction in relation to the time for the sliding speed $\mathrm{v}=10 \mathrm{~mm} / \mathrm{s}$, steel pin, for the normal load of $10 \mathrm{~N}$. The duration of the test was about 1 minute, and the coefficient of friction is in this interval a nonlinear variation, starting from the lowest value 0.16 to a value of 1.28 . The variation of the friction coefficient is justified by the fact that the non-uniformity of the surface determines the probe to pass through smooth areas and rough areas with a relatively high alternation.

\section{Scratch test used to evaluate mechanical properties}

The scratch test is based on ASTM C 1624 and is used to determine substrate adhesion strength and breaking modes, from the substrate.

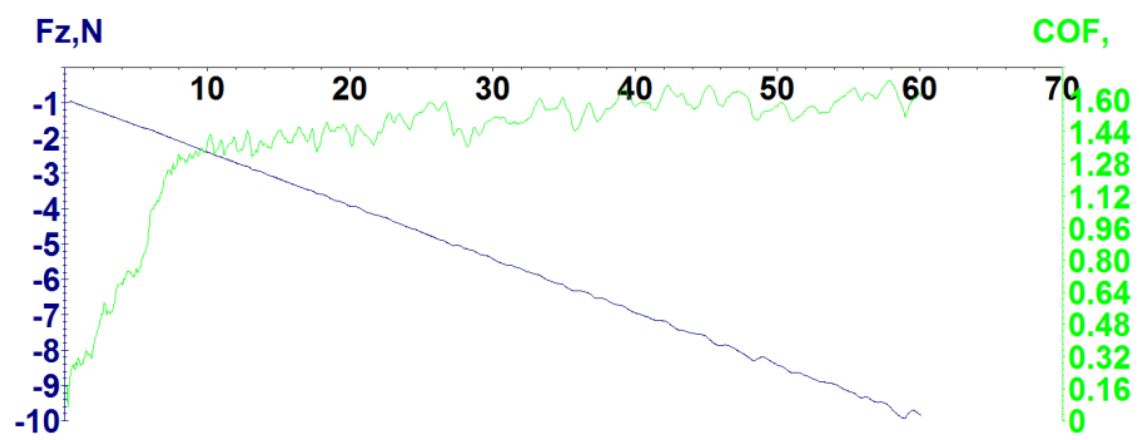

Time,sec

Fig. 3. The graph generated during the scratch test, the variation of the coefficient of friction as a function of the applied force

Using the data in the graph shown in figure 3, it was calculated that the footprint started to occur in 10 seconds, corresponding to a force of $10 \mathrm{~N}$. On the same graph there are large variations in the coefficient of friction from 0.16 to 1.60 , caused by the porosity of the layer, subsequently remaining around these values.

The Al-Si alloy under investigation was not visibly affected by the adhesion test (fig. 4). 

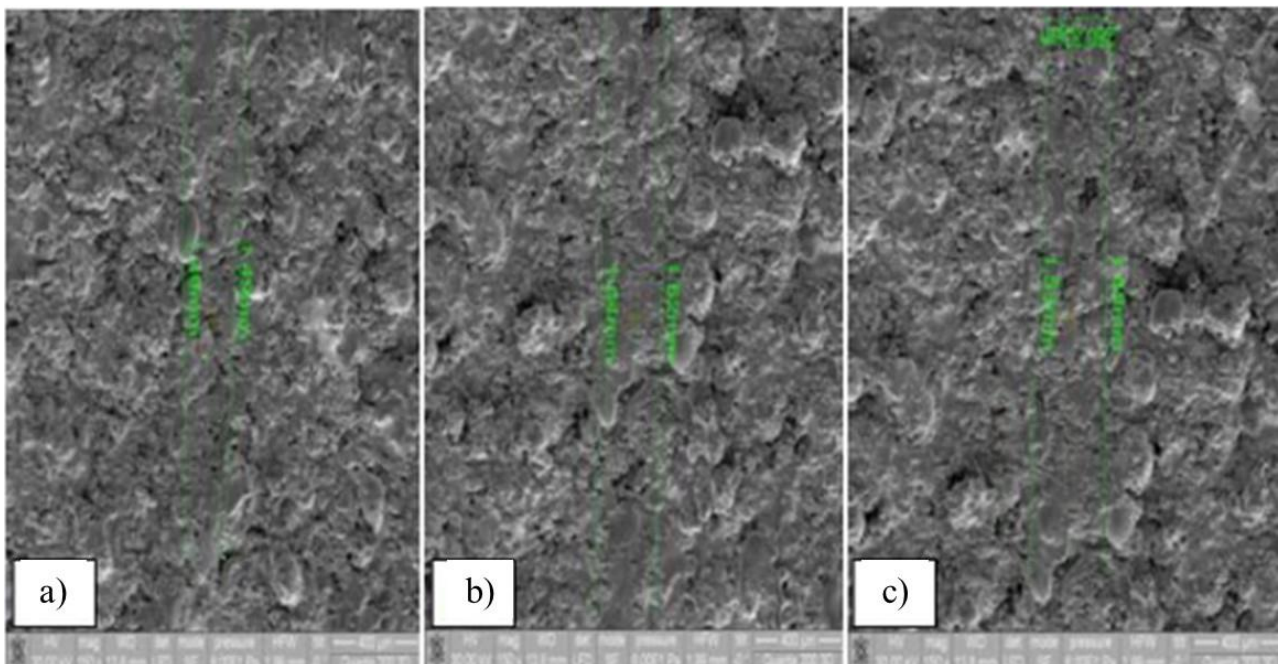

Fig. 4. Image of secondary electrons of the "scratch" in the case of the Al-Si test:

a) the initial zone, b) the intermediate zone and c) the final zone

Following the graph generated during the test by the variation of the coefficient of friction depending on the applied force, three areas of the - scratch were presented: the initiation zone (corresponding to the application of a force from $0 \mathrm{~N}$ to $3 \mathrm{~N}$ ), an intermediate zone $(3-6 \mathrm{~N})$ and the final area $(6-10 \mathrm{~N})$ in order to be able to observe the behaviour of the Al-Si alloy. SEM micrographs confirm that the Al-Si alloy does not show visible damage.

\section{Conclusions}

Wear is "a progressive loss of material on the surface of a solid body due to mechanical action, which is in contact and in relative motion with another solid body, liquid or gas." The phenomenon of wear is a rather difficult subject to understand because there are many factors involved (such as the contact temperature, the geometry of the contact the chemical and physical properties of the materials of the bodies in contact, etc.).

Wear as a process is usually ignored in the design of mechanical systems, which in many cases leads to significant maintenance costs, which lead to extremely high costs. Thus, durability design without regard to local effects, wear and corrosion leads to premature and unexpected failures in many technical applications.

The variation of the coefficient of friction in relation to time (approximately 1 minute) shows a non-linear variation, starting from the lowest value of 0.16 to a value of 1.28 . The variation of the friction coefficient is justified by the fact that the non-uniformity of the surface determines the probe to pass through smooth areas and rough areas with a relatively high alternation.

The scratch test analysis provides indications on the surface properties of the studied sample, namely the friction characteristics and the resistance to contact pressure. The sample analysed from Al-Si has a relatively low coefficient of friction and high resistance to point contact.

Due to the malleable properties of aluminium, the scratch test penetrator forms a pressure channel with smooth edges, without adhesions and microcracks on the entire contact area. Scratch test indicates that $\mathrm{Al}-\mathrm{Si}$ alloy is a high resilience material, which is recommended in the use of parts with direct contact and medium force actuation. 


\section{References}

[1] M. Kemal, B. Ahmet, I. Yukler, Effects of welding parameters on friction stir spot welding of high-density polyethylene sheets, Materials \& Design, 33 (2), 2012, pp. 545-550.

[2] Z. Liu, H. Zhang, Z. Yan, P. Dong, Enhanced fatigue performance of aluminum alloy through surface strengthening treatment, Materials Letters, 306 (1), 2022, pp.130-141.

[3] D.C. Gianluca Buffa, A. D'annibale, D.I. Antoniomaria, L. Fratini, Experimental and numerical study on linear friction welding of AA2011 aluminum alloy, Key Eng. Mater., 611-612, 2014, pp. 1511-1518.

[4] A. Rotundo, A. Marconi, A. Morri, Dissimilar linear friction welding between a SiC particle reinforced aluminum composite and a monolithic aluminum alloy: microstructural, tensile and fatigue properties, Mater. Sci. Eng., A, 559, 2013, pp. 852-860.

[5] E. Dalgaard, P. Wanjara, G. Trigo, M. Jahazi, G. Comeau, J.J. Jonas, Linear friction welding of Al-Cu part 2 - interfacial characteristics, Can. Metall. Q., 50, 2011, pp. 360-370.

[6] I. Bhamji, M. Preuss, P.L. Threadgill, R.J. Moat, A.C. Addison, M.J. Peel, Linear friction welding of AISI 316L stainless steel, Mater. Sci. Eng., A, 528, 2010, pp. 680-690.

[7] G. Buffa, G. Campanile, L. Fratini, A. Prisco, Friction stir welding of lap joints: influence of process parameters on the metallurgical and mechanical properties, Mater. Sci. Eng., A, 519, 2009, pp. 19-26.

[8] H.R. Chamani, M.R. Ayatollah, The effect of Berkovich tip orientations on friction coefficients in nanoscratch testing of metals, Tribology International, 103, 2016, pp. 2536.

[9] D.K. Sahoo, B.S. Mohanty, A.M. Pradeep, A.D.F. John, An experimental study on friction surfaced coating of Aluminium 6063 over AISI 316 stainless steel substrate, Mater Today: Proceedings, 40 (1), 2021, pp. 10-18.

[10] O.K. Panagouli, K. Mastrodimou, Dependence of friction coefficients on the resolution of asperities in metallic rough surfaces under cyclic loading, International Journal of Solids and Structures, 108, 2017, pp. 85-97.

[11] D. Choudhury, M. Vrbka, A. Mamat, I. Stavness, C.l Roy, R. Mootanah, I. Krupka, The impact of surface and geometry on coefficient of friction of artificial hip joints, Journal of the Mechanical Behavior of Biomedical Materials, 72, 2017, pp. 192-199.

[12] S.M. Shafaei, S. Kamgar, A comprehensive investigation on static and dynamic friction coefficients of wheat grain with the adoption of statistical analysis, Journal of Advanced Research, 8(4), 2017, pp. 351-361.

[13] C. Wang, R. Ma, J. Zhao, J. Zhao, Calculation method and experimental study of coulomb friction coefficients in sheet metal forming, Journal of Manufacturing Processes, 27, 2017, pp 126-137.

[14] P. Plescia, E. Tempesta, Analysis of friction coefficients in a vibrating cup mill (ring mill) during grinding, Tribology International, 114, 2017, pp 458-468.

[15] P. Kumar, Y. Gajendra, D. Savit, D. Virendra, P. Singh, , Effect of eutectic silicon and silicon carbide particles on high stress scratching wear of aluminium composite for various testing parameters, Wear, 482-483, 2021, 203921

[16] R. Parthiban, J. Radha, Investigation of mechanical properties of friction stir welding aluminium alloy AA7475-T651 and AA2219-O, Materials, 47 (19), 2021, pp. 150-161 
[17] E. Seidi, S.F.Miller, Lateral friction surfacing: experimental and metallurgical analysis of different aluminum alloy depositions, Journal of Materials Research and Technolog, 15, 2021, pp. 5948-5967.

[18] H. Li, W. Qin, A. Galloway, A. Toumpis, Friction surfacing of aluminium alloy 5083 on DH36 steel plate, Metals, 9 (4), 2019, pp. 479-488

[19] M.Varga, L. Grossb, H. Rojacza, S.J. Ederac, M. Grillenbergerd, M.R. Ripolla, Scratching aluminium alloys - Modelling and experimental assessment of damage as function of the strain rate, Wear, 476, 2021, 203670

[20] D.K. Sahoo, B.S. Mohanty, A.P. Maalika Veetil, Evaluation of bond strength and flash mass on friction surfaced deposition of aluminium 6063 over IS 2062 low carbon steel using different mechtrode face, Ann Chimie Sci Matériaux, 44 (2), 2020, pp. 109-119.

Received: September 09, 2021

Accepted: October 14, 2021 